\title{
Test of anti theft alarm system for oil well
}

Song Limei ${ }^{1, a}$, Liu Shuangjin ${ }^{2, b}$, LI hexiang ${ }^{3, c}$ Ge dongwen $^{4, d}$ Songhuimei ${ }^{5, e}$ 1,2,3,4,5 The Second Oil Exploitation Unit of Huabei Oil Field PetroChina China

${ }^{a}$ cy2_gcslm@petrochina.com.cn

${ }^{b}$ cy2_czlsj@petrochina.com.cn

ccy2_czlhx@petrochina.com.cn

dcy2_gdw@ petrochina.com.cn

ecy2_dzshm@petrochina.com.cn

Keywords:oil well, anti-theft, alarm system

Abstract :In recent years, the oil stolen event has occurred, to the safe production of oil wells has brought hidden danger. In the pumping oil wells wellhead anti-theft take in at the middle part of the installation of three detectors, on the Christmas tree install one-way flow meter and other security measures, but the problems are no security equipment itself, high false positive and non-response rates. The optical fiber vibration type oil well anti-theft remote monitoring alarm device is mainly composed of an optical fiber sensor, a front-end processor, a mobile terminal and a display controller. Principle is through the detection of the vibration signal around the well, whether around the well have unusual, and the simulation test for winter summer. The system has the advantages of good concealment, anti-interference, strong adaptability, good reliability, simple realization and so on, to provide technical reserves for video alarm linkage system.

\section{Introduction}

Oil theft and damage had sometimes occurred in pumping oil well, which brings hidden trouble to the safe production of oil wells. In order to reduce oil theft and facility damage, we once took kinds of theft prevent methods, including installing three-kam detector in the middle axis of pumping oil machine, composing of installing unidirectional flow meter and video system as alarm linkage, which could be regard as theft prevent system. However, these products have some drawbacks, such as no self anti-theft, false alarming and under-alarming. For solving these problems, we developed Remote Monitoring and Alarming System of Oil Well Anti - theft Based on Optical Fiber Vibration. In the system, the acquisition front-end is buried in the ground, and therefore it can overcome self-safety defects. Moreover, it can be the technology storage for oil well alarming linkage system after the successful test.

\section{Anti-theft and Alarm system}

\section{Principles}

In the absence of external shocks and pressure changes, the laser beam along the cable to the receiver of the optical signal is a stable line. When the optical cable gets external shocks and pressure changes, the laser beam will produce small changes, and then the photoelectric converter will convert a slight change in light movement into electrical signals. Therefore, the analysis 
software will choose the appropriate waveform to implement the processing[1], as following Figure 1:

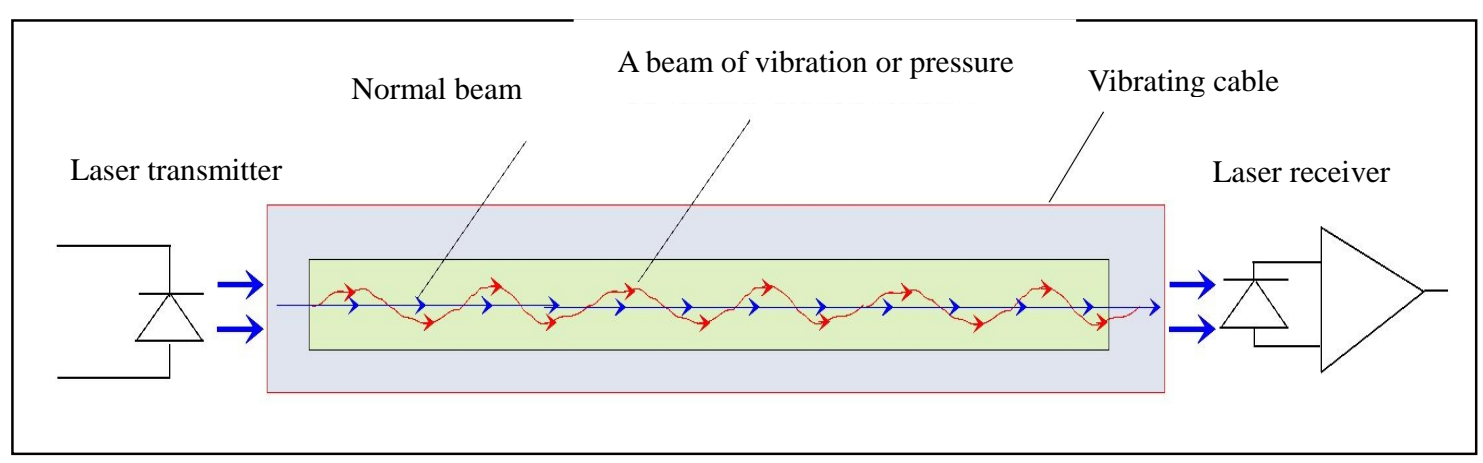

Figure 1 principle of monitoring and alarming device

\section{Composition}

The system is mainly composed of optical fiber sensor, front-end processor, mobile terminal and display controller.

A. Optical fiber sensor consists of an ordinary 4-core communication cable, laser emitter and the receiver. Its role is to detect vibration and gravity changes in the monitoring area

B. Front-end controller is mainly composed of the photoelectric converter, analysis and processing software, GPRS wireless transmitter module and power components. The signal processor converts the light beam running change detected by the optical fiber sensor into an electric signal, and selects the corresponding waveform signal by an independently developed analysis software and processes it into an alarming signal, and sends it into the GPRS module for transmission. The power conversion and battery group provide the monitoring equipment with power and ensure it can continue to work for 24 hours in the case of cutting off external power supply.

C. The mobile display terminal, which is composed of GPRS receiver module, LCD screen and power battery, can display all the alarm information around the LCD screen. With the switch output function, it can be used with other systems like video camera positioning system[2], as following Figure 2.

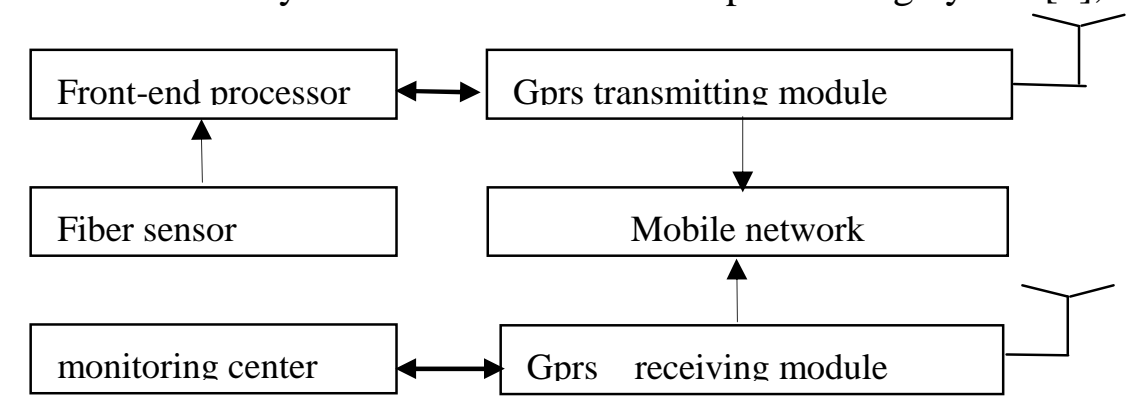

Figure 2 Schematic diagram of oil well anti-theft alarm system

\section{Features}

a. By vibration and dynamic gravity detection principle, only an object, which has a certain weight touch the detection areas can trigger the alarm and maximize to overcome false alarming and under-alarming phenomenon.

b. The use of optical sensing technology brings strong anti-interference ability, to avoid the false alarming caused by on-site power, environmental electromagnetic waves, thunderstorms and other adverse weathers. 
c. Detection cable and front-end processor was buried at the half a meter in the ground, thus it can not be easily found and damaged by intruders, which has strong self-protection and concealment features. Moreover, it also has alarm functions in case of dismantling and cutting off power. And meanwhile, the system can send alarm information to remote terminal when the testing equipment damaged and AC power supply cut off.

d. By utilizing wireless GPRS transmission technology, the system can achieve the transmission and reception o the alarm signal as long as in the mobile GPRS network signal coverage areas. So, the technology breaks through the geographical limits and the terminal display can be placed anywhere based on the requirements ${ }^{[3]}$.

e. AC and battery dual power supply can let field equipment continue operating for 24 hours when the power cut off.

f. Integrated switch interface output has linkage control with other third-party equipment such as video monitoring. Monitoring center can not only directly monitor the situation of oil stolen and state of pump operating, but also remotely control start or stop of the pumping machine ${ }^{[4]}$.

\section{Main Technical Specifications}

Power Supply: Voltage of testing host is AC 220V, Power $<=5 \mathrm{~W}$ and Voltage of display terminal is AC 220V Power $<=8 \mathrm{~W}$, Environment Temperature: $-40-70^{\circ} \mathrm{C}$;Power off time: $<=120 \mathrm{~h}$

Protection range: $<=5$ Square meters;Buried depth: $<=50 \mathrm{~cm}$;Sensitivity: weight $>=50 \mathrm{~kg}$ frequency $>=1 / \mathrm{s}$ Alarm duration: $1-10$ s adjustable; Error and false rate: $<=1 / 24 \mathrm{~h}$.

\section{Well Selection and Installation}

\section{well Selection}

This well is relatively far away from crossing, and not easily to be found by criminals when testing; this well's theft is serious; camera can be used to double check once alarm occurs. After onsite investigation by technicians, we selected Cha 76-13 Well as testing well.

\section{Installation}

a. Preferred installation area selection:the eastern pipeline point is the drain point, and oil theft activities mainly occur in the area of 5 square meters within the area. Therefore, the north and south part of the wellhead would be set as the key protection areas. Detection cable put in this area $50 \mathrm{~cm}$ depth underground, once the criminals enter this area, they will step the detection cable and trigger alarming, as following Figure 3 .

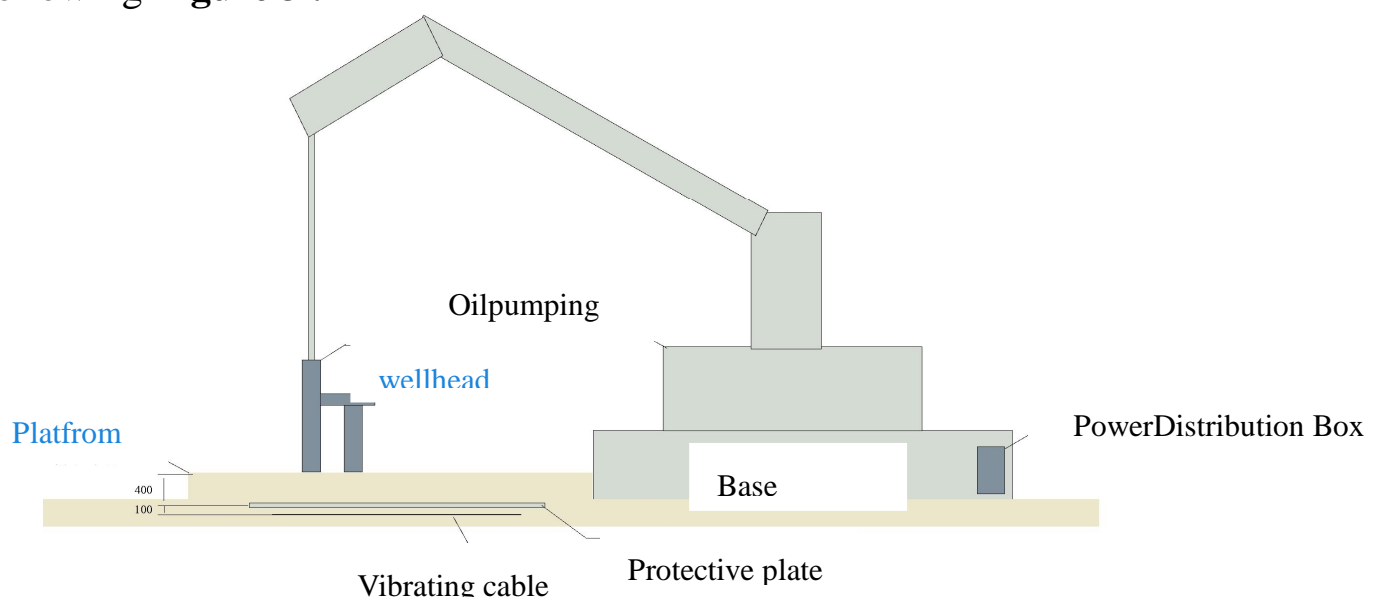

Figure 3 installation diagram 


\section{b. Installation layout optimization}

U-type vibration fiber is installed $300 \mathrm{~mm}$ far away from the wellhead. Around the fiber, there is $1 \mathrm{~mm}$ steel plate as protection and optical transceiver buried under the steel plate, connection the cable and detection host hidden depth of $70 \mathrm{~cm}$ or less, as follows Figure 4.

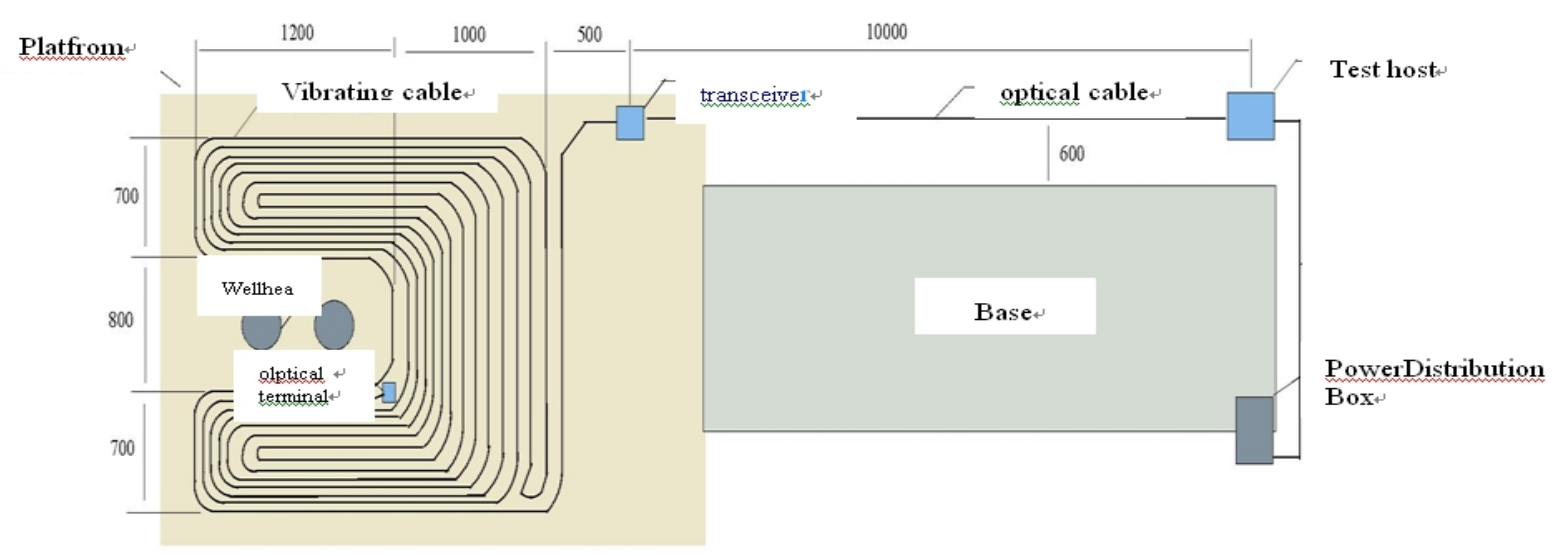

c. Main parameters determination

Figure 4. Installation view

1. Excavation the pit along the wellhead platform with length, width $2.5 \mathrm{~m}$, depth $0.5 \mathrm{~m}$. Excavation the deep groove along the pumping unit based to distribution box.

2. Under the $0.5 \mathrm{~m}$ depth of wellhead platform, along well laying the U-type detection cable reciprocally.

There is $5 \mathrm{~cm}$ between two cables, and between north and south it is $70 \mathrm{~cm}$, and between east and west it is $120 \mathrm{~cm}$. Optical terminator and transceiver together are buried in the wellhead platform. In order to increase the protection ability of the detection equipment, we cover $1 \mathrm{~mm}$ iron plate with detection cable and front-end equipment. Consequently, it can avoid man-made tackling damage. Detection host is buried at $80 \mathrm{~cm}$ underground and $10 \mathrm{~m}$ away from the wellhead platform.

\section{Onsite Debugging}

\section{Pumping Unit Interference Filter}

After the detection cable and front-end detection equipment are installed, the next step is onsite debugging. The testing host is connected with the external computer through the Ethernet port. When starting debugging software, at first, the system connection test is conducted to judge whether the connection between the detection cable and the testing host is good, then go to set vibration cable parameters.

There are two large vibration interference sources around the oil well, namely the vertical vibration of oil well and the horizontal vibration of pumping unit. The frequencies of two vibrations are not nearly the same, but the amplitude is bigger than that caused by people stepping on detection cable. Thus, it leads that the vibration caused by people entering the optical fiber deployment area is overlapped by that because of well and pumping unit. The existing vibration analysis software cannot extract the distinctions, but it extracts field waveform data to be further research and improvement. As shown in Figure 5, the first $60 \mathrm{~s}$ is the background (caused by the vibration of the wellhead and the pumping unit), there is a walking behavior on the wellbore between 60s-70s. After $70 \mathrm{~s}$, it is also background. From the picture, it is very difficult to distinguish walking behavior from 
background. (Note: The horizontal unit is second, the total time is 100s, the vertical axis is the amplitude, and the amplitude unit is $\mu \mathrm{m}$ ). According to the vibration data extracted in the field, the following two changes are made to the analysis software: one is to increase software filters and integrators, to maximize the reduction and deformation of interference wave amplitude on the wellhead. Another one is to add the extracted wellhead vibration waveform data after reduction and shaping to the background feature library. By the adaptive learning function of software, the onsite wellhead and pumping unit vibration are determined as the invalid vibrations, and can be distinguished with the vibration by human body walking.

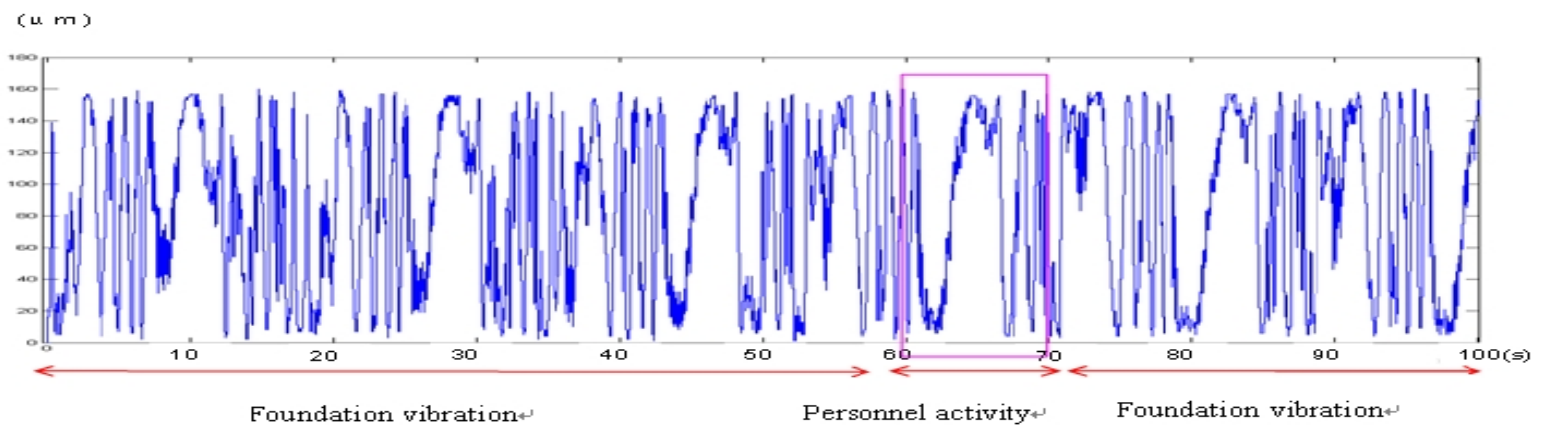

Figure5 Basic vibration and personnel walking waveform

With the new analysis software for debugging, we can clearly see people walking on the wellhead platform through the observation of the waveform diagram, as show in Figure 6: the first 30s is background(caused by vibration from wellhead and pumping unit). There is walking behavior on the wellbore between 30s-40s. After 40s, it is also background. (Note: The horizontal unit is second, and the total length is 50s; the vertical axis is the amplitude and the amplitude is the unit of $\mu \mathrm{m}$ ). The two waveforms are obviously different and can be easily distinguished from each other. Repeating different forms of human walking, it will be stored in the software feature library. Once the detection of similar waveforms will trigger the alarm. After the second debugging, we believe that to achieve the desired effect.

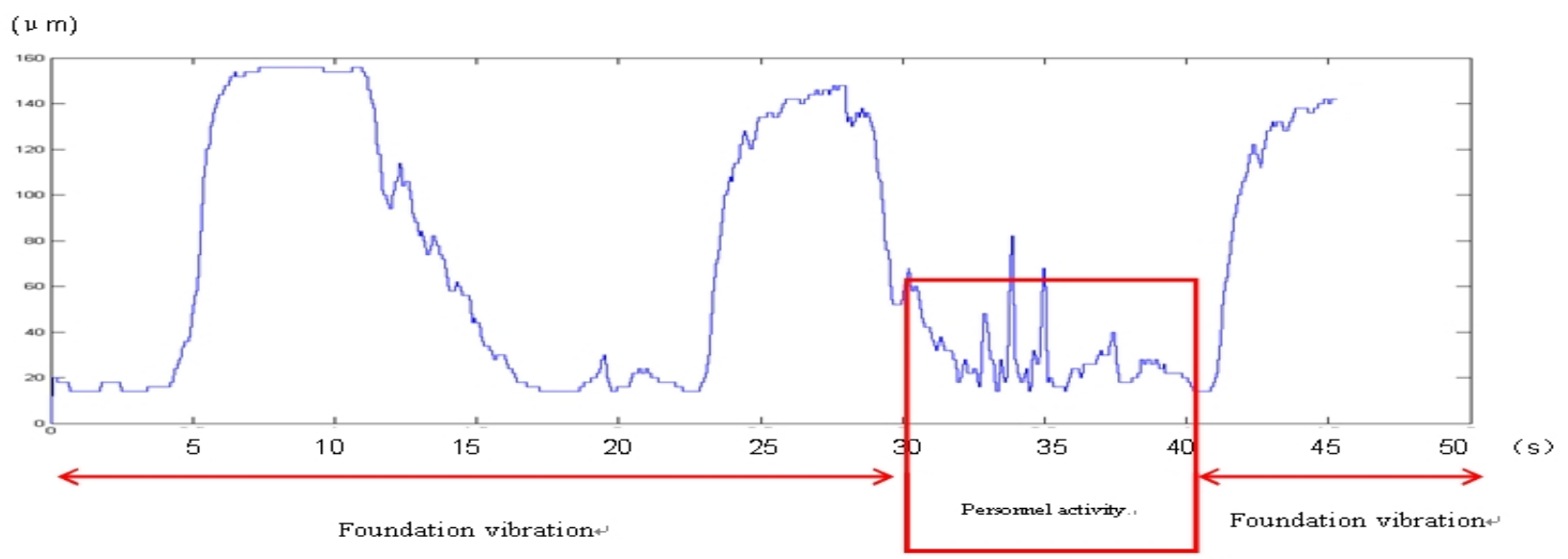

Figure6 After the modification of the software, the basic vibration and personnel walking waveform

\section{Wellhead vibration filtering}

Delivering the wireless terminal alarm host to the technical staff in the operating area, technical staff will observe the operation of the alarm system. Observed by 24 hours, during that, there were 8 times alarm, and 2 alarms for the staff to enter, however, the left 6 alarms were confirmed as false alarms. And then after careful testing and analysis on the wellhead, we can determine the false 
alarms were caused by wellhead vibration. This vibration is an occasional sporadic vibration, not continue to occur. We can do the following adjustments on the setting of parameters through the window software: At first, the vibration intensity slope is changed from 15 to 21 , and the sensitivity of the perceptual vibration is reduced. Secondly, the number of detection windows and events is changed from 1 time every 3 seconds to 5 times every 9 seconds, and this action can avoid 1-4 false alarms caused by vibration in 10 seconds, but has no effect on occurring alarm when walking. Because it usually takes several tens of minutes to steal the oil, and the number of moves will not be less than 5 steps.

\section{stability verification}

Mastering the field alarm situation through wireless terminal, during the testing period, alarm system worked properly, no false alarm occurred. Please see the alarm monitoring data in table 1.

\begin{tabular}{|l|l|l|}
\hline \multicolumn{1}{|c|}{ Time } & \multicolumn{1}{c|}{ Alarm description } & \multicolumn{1}{c|}{ Remarks } \\
\hline 2015.03 .15 & $19: 50 ; 22: 43 ; 1: 11 ; 2: 36$ & The accuracy rate was $100 \%$ \\
\hline 2015.03 .16 & $7: 58 ; 9 ; 06 ; 9: 15 ; 10: 26 ; 16 ; 15$ & $\begin{array}{l}\text { Pumpingunit vibration,the } \\
\text { modification procedures }\end{array}$ \\
\hline 2015.03 .17 & $6: 21 ; 12: 30 ; 15: 30$ & $\begin{array}{l}\text { After the program is updated, the alarm normal } \\
\text { pumping unit vibration }\end{array}$ \\
\hline 2015.03 .18 & $13: 51-13: 57 ; 22: 31$ & 5 times can alarm, accuracy rate of $100 \%$ \\
\hline 2015.03 .19 & $9: 50 ; 23: 03$ & Alarm normal \\
\hline 2015.03 .20 & $9: 28 ; 15: 24 ; 23: 28 ;$ & Alarm normal \\
\hline $2015.03 .21 / 22$ & $5: 34 ; 5: 48 ;$ & Alarm normal \\
\hline 2015.03 .23 & $17: 16 ; 22: 46 ; 23: 52$ & Alarm normal \\
\hline 2015.03 .24 & $11: 07$ & Alarm normal \\
\hline 20.15 .03 .25 & $2: 23 ; 11: 35 ; 21: 32$ & Alarm normal \\
\hline $2015.03 .26 / 27$ & $11: 44 ; 16: 29$ & Alarm normal \\
\hline
\end{tabular}

\section{Conclusions}

a. The anti-theft alarm system has better concealment feature, which is suitable for the harsh environment, especially high demand of self-protection and concealment. No damage has been found during the testing time.

b. The main technical parameters of the device can meet the target of onsite anti-theft, and have effective monitoring and alarming functions for the oil-theft on pumping wellhead and destruction of the wellhead facilities, etc. and provide effective monitoring data for the personnel on duty.

c. The signal transmission is good. During the test, the terminal monitoring device installed in the remote can receive all the signals and data sent by alarm device. During the simulation process of summer and winter, after several consecutive blackouts and continuous rainy days, it still worked stably, and there were no equipment damage and signal interruption.

\section{Reference:}

[1] Wen, Haikun, Remote Monitoring System for Oil Well [j]. Electronic Measurement Technology. 2008,31(1):p105-107;

[2] Zhang, Ren, Oil Well Burglar Alarm System Based on Mobile Phone Module [j]. 
Instrumentation \& Electricity, 2013,32(7): p88-89;

[3] Wang, Yutian, Remote Monitoring System for Oil Well Based on GPRS [j]. Instrumentation Technology \&Sensor, 2009(9):p 45-47;

[4] Zhou,Feng . Energy - saving Monitoring System of Intelligent Distributed Pumping Unit Based on GPRS [j]. Instrumentation Technology, 2008 (3):p 1-2 . 